\title{
Hepatobiliary Ascariasis
}

\author{
Omesh Goyal', Deepinder Kaur², Rajdeep Singh ${ }^{3}$, Pooja Suri², Prerna Goyal ${ }^{4}$ \\ ${ }^{1}$ Departments of Gastroenterology, ${ }^{2}$ Microbiology, ${ }^{3}$ Social and Preventive Medicine, ${ }^{4}$ Medicine \\ Dayanand Medical College and Hospital, Ludhiana, Punjab, India
}

\begin{abstract}
Ascaris lumbricoides is one of the commonest human parasitic infestations in the developing world. Most of the ascaris infections are asymptomatic and clinical disease is mainly restricted to subjects with heavy worm load. Biliary migration of the worm can lead to a wide variety of clinical syndromes and concomitant complications necessitating early diagnosis and management. Various disease presentations include biliary colic, obstructive jaundice, acalculous cholecystitis, choledocholithiasis, pancreatitis, cholangitis, biliary strictures and hepatic abscesses. While laboratory tests are non-specific, radiological investigations demonstrate features highly suggestive of biliary ascariasis. The vast majority of patients respond to conservative measures. Endoscopic therapy is necessary in cases which fail to respond to conservative measures or in patients presenting with complicated disease. Worms visible at the ampulla may be extracted endoscopically prior to attempting more intrusive forms of therapy. Sphincterotomy should be avoided for worm extraction since an open biliary sphincter facilitates future disease recurrences should worm reinfestation occur. Recurrence of the disease is frequent due to re-infestations. Worm eradication with anti-helminthic therapy is essential after biliary disease resolution.
\end{abstract}

Keywords : Ascaris lumbricoides, ERCP, Hepatobiliary ascariasis

\section{INTRODUCTION}

Ascariasis, caused by nematode Ascaris lumbricoides, is the most common helminthic infection of mankind. ${ }^{1}$ It is widely prevalent in developing tropical and sub-tropical countries. The infection is acquired by ingestion of embryonated eggs. Although the adult ascaride normally resides in the small intestine, it has been known to migrate to various regions of the body such as lungs, urinary bladder, peritoneum, and biliary system. Worm migration to ectopic sites is influenced by conditions such as fever, drug intake, general anesthesia, and bowel manipulation during surgery. Hepatobiliary ascariasis (HBA) is characterized by migration of the worm into the biliary tree, and accounts for 10-19\% of ascaris-related hospital admissions. ${ }^{2,3}$

\section{EPIDEMIOLOGY AND RISK FACTORS}

Ascaris lumbricoides affects over one billion people worldwide. ${ }^{4}$ While ascariasis is most prevalent in the

\section{Corresponding Author :}

Dr Omesh Goyal

Department of Gastroenterology

Dayanand Medical College and Hospital

Ludhiana, Punjab, India

Email - goyalomesh@yahoo.co.in tropical and sub-tropical countries of the developing world, its prevalence in the industrialized nations is increasing as a result of population migration. ${ }^{5,6}$ The most endemic areas include Africa, the far East, Latin America, southeast Asia, and some parts of the Middle East. ${ }^{7-12}$ The prevalence rates in China and south-east Asia range from $41-92 \% .{ }^{13}$ In the Indian subcontinent, Ascariasis is highly endemic in Kashmir (70\%), Bangladesh (82\%) and central and southwest India (20-49\%). ${ }^{13}$

In endemic areas, the prevalence of Ascariasis increases sharply during the first 2 to 3 years of age, remains at a maximum between the ages of 4 and 14 years, and declines in adults. ${ }^{1}$ However, HBA is more common in adults (mean age 35 years; range $4-70$ years) as compared to children, possibly due to the smaller papillary orifice in children. ${ }^{8} \mathrm{HBA}$ affects women more commonly than men (female:male ratio - 3:1). ${ }^{1,9,10,14}$ Pregnant women are more prone to develop HBA as compared to non-pregnant women. ${ }^{15}$

Pre-disposing factors for HBA include previous cholecystectomy, ${ }^{16}$ endoscopic sphincterotomy ${ }^{17}$ or even prolonged fasting. ${ }^{10}$ Studies have shown that almost $30 \%$ of patients with biliary ascariasis have a prior history of cholecystectomy. ${ }^{16}$ Dilatation of the common bile duct (CBD) as well as relaxation of the sphincter of Oddi due to a rise in cholecystokinin levels after cholecystectomy 
are the contributory factors for worm migration into the biliary tree. Endoscopic sphincterotomy predisposes to HBA due to widened ampullary orifice allowing easier passage of worms into the ducts. ${ }^{18}$

\section{Clinical Presentation}

Most of the Ascaris infections are asymptomatic. Patients with heavy worm load are often symptomatic and represent an estimated 1.2 to 2 million cases around the world. ${ }^{1}$ It is estimated that around 20,000 deaths occur every year because of severe disease caused by ascariasis.

\section{Hepato-biliary}

HBA is one of the most common and well-described entities caused by ascariasis. ${ }^{1}$ In endemic areas, ascariasis has been found to be equal in incidence to gallstones as an etiological factor for adult biliary disease. ${ }^{1,9}$ Ascaris reaches the duodenum either because of excessive worm load in jejunum or due to abnormal mobility after intestinal infection with viruses, bacteria or other parasites. Due to its great propensity to explore small openings, ascarides enter the ampullary orifice. ${ }^{1,19}$ It can block the ampullary orifice or can move further into bile duct, hepatic duct or cystic duct. Ascarides have been seen to move actively in and out of the bile duct from the duodenum. Less commonly, the worms can reach the gall bladder or enter the pancreatic duct. Ascaris worm or its fragments may act as a nidus around which the stones form..$^{8,920,21}$ This process is aided by factors such as bile-stasis and ascending bacterial infection. HBA can have various distinct clinical presentations:

a) Biliary colic: It is the most common presenting symptom of HBA with a frequency ranging from 56 to $98 \% .^{8-10}$ Biliary colic occurs when the worm migrates across the papilla. Patients present with acute pain in the right hypochondrium associated with nausea and vomiting. The pain may be severe, prolonged or recurrent in nature requiring high doses of analgesics. ${ }^{1}$

b) Acalculous cholecystitis: It is another major complication of HBA, accounting for about $10 \%$ of the cases of acute cholecystitis. Patients present with pain in the right hypochondrium, associated with vomiting and low-grade fever. Tenderness and guarding in the right hypochondrium is usually present. ${ }^{1}$

c) Ascending cholangitis: Acute chalongitis may occur in 16 to $25 \%$ as a consequence of persistent biliary obstruction. ${ }^{8-10,12}$ Patients present with right hypochondrial pain, high-grade fever and jaundice. Examination reveals an enlarged tender liver and leucocytosis. Untreated cases may develop hypotension and metabolic acidosis.

Strong epidemiological evidence supports that in endemic areas of ascariasis, recurrent pyogenic cholangitis (RPC) is the aftermath of recurrent biliary invasion by ascariasis. ${ }^{21} \mathrm{RPC}$ and ascariasis have similar geographic distribution. More than $5 \%$ of patients with HBA develop the syndrome of RPC over a 2 year follow-up. In addition, $10 \%$ of patients with RPC have documented evidence of ascariasis, and $72 \%$ of patients with RPC reveal Ascaris worm or worm fragments forming nidus for stones. ${ }^{1,13}$ Association between cholangiocarcinoma and biliary ascariasis has been reported infrequently. ${ }^{22,23}$

d) Acute pancreatitis: Acute pancreatitis occurs in 4-36\% of patients with pancreato-biliary ascariasis. . $^{8,10,12}$ It accounts for most of the mortality associated with biliary ascariasis. Patients present with vomiting and epigastric pain radiating to back. Most of the patients (90\%) have mild disease, however, in $10 \%$ cases the pancreatitis is severe. A small group of patients who have massive ascariasis invasion develop haemorrhagic pancreatitis which is associated with high mortality.

e) Liver abscess: Liver abscess occurs due to parenchymal invasion by high worm leading to local inflammation, necrosis, and abscess formation. In HBA, liver abscess occurs in less than 1-14.5\% of patients, the frequency being higher in endemic areas. ${ }^{8,10}$ Javid et al described 510 patients with liver abscess in whom 74 (14.5\%) had ascariasis as the source of infection. ${ }^{24}$ Patients present with right upper quadrant pain, fever and tender hepatomegaly.

\section{Intestinal}

Ascaris induced intestinal obstruction is a common complication in children with heavy worm loads in endemic areas, accounting for $5-35 \%$ of the cases of bowel obstruction in these areas. ${ }^{13}$ The most common site of blockage is the terminal ileum. Intussusception, vlovulus, haemorrhagic infarction of the bowel, and perforation may occur due to prolonged obstruction. ${ }^{2}$

Peritonitis may occur if the ascarides enter the peritonel cavity through the gangrenous bowel wall or through a perforation caused by ulcer due to other etiology. The peritonitis may be fatal; and if the patient 


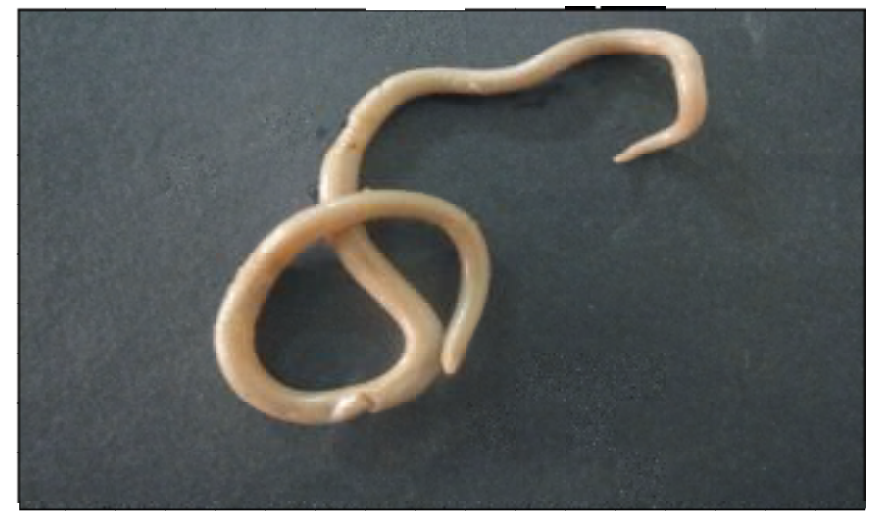

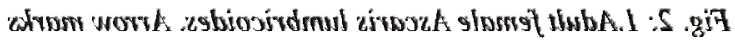

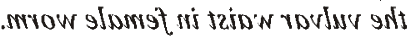

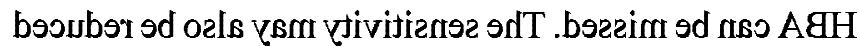

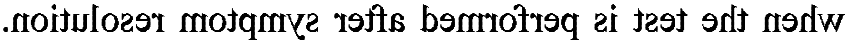

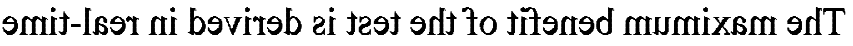

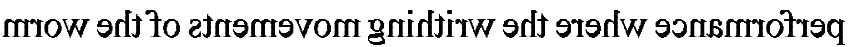

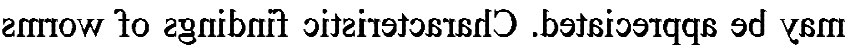

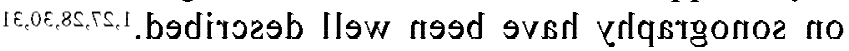

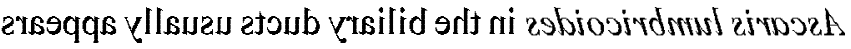

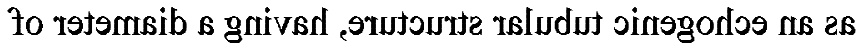

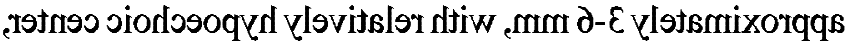

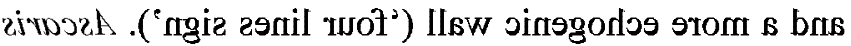

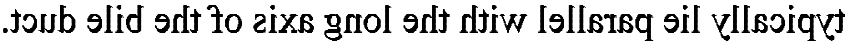

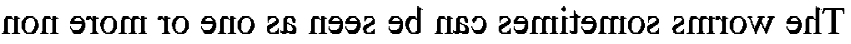

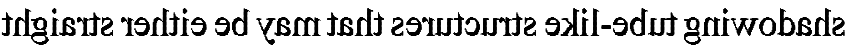

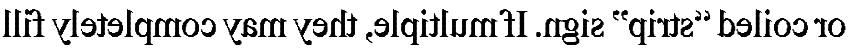
ti 1o e"

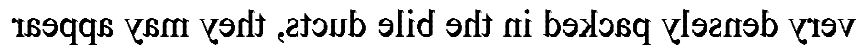

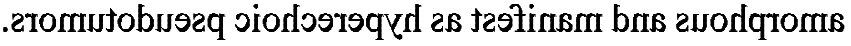
эgbula esmэb cnoifnэtaib эbuloni agnibnilt rэbbsldllsD

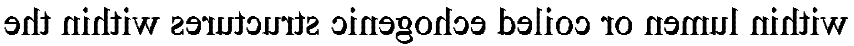
.tobbsild Ilsg

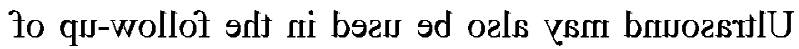

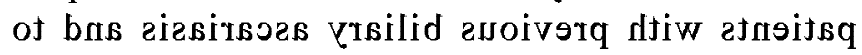

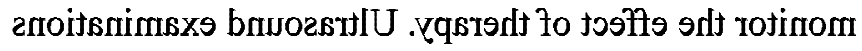

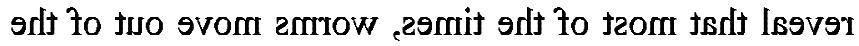

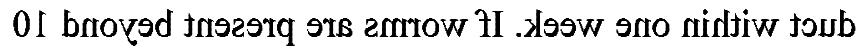

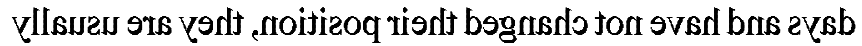

.bsob

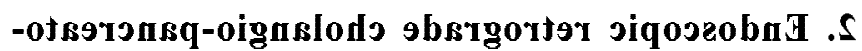

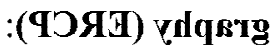

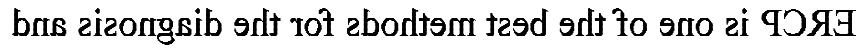

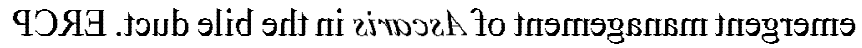
efimmsq fi es loof jifeongsib s as ggstnsubs ns asd saonlt bns munnsboub silt ni amrow onlt to noitsoitifnsbi nirffiw ammowbnisor to noifsitantoms .slliqsq onlf zaotos

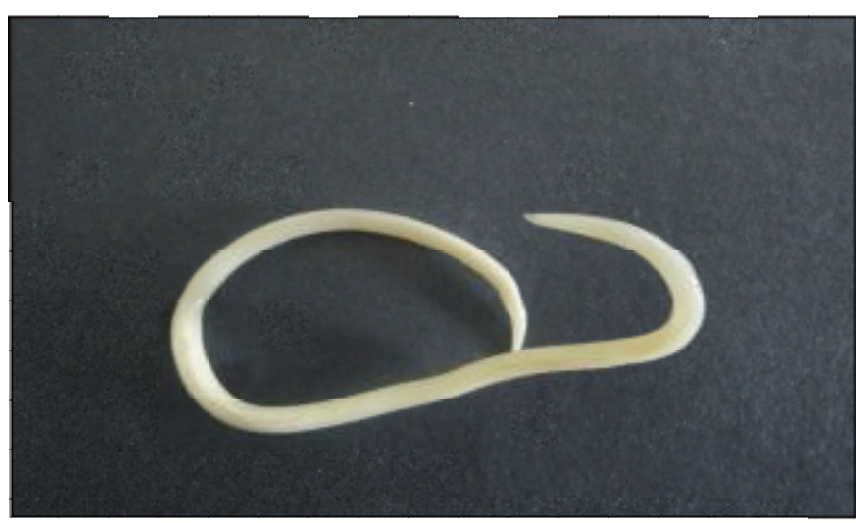

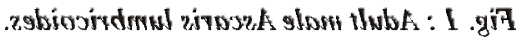

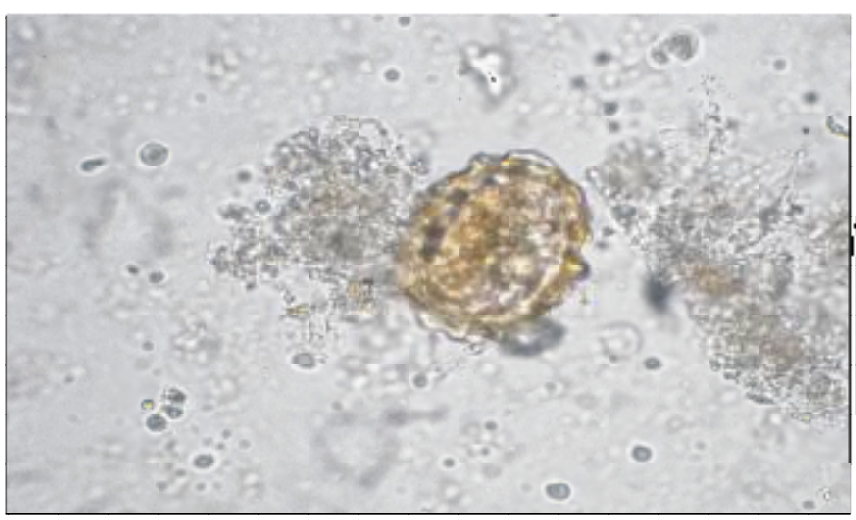

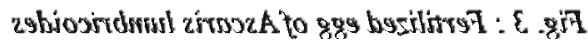

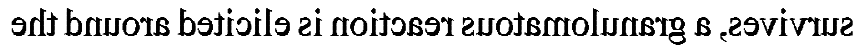
anofsmolunistg jintorno s of gnibsol enrow bststgstnizib

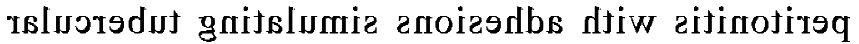
eșê.eitiniotiryq

ZIZOVDAIU

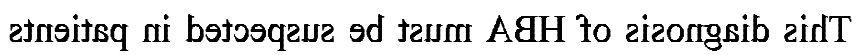

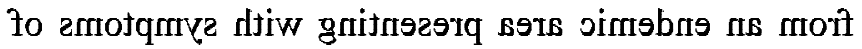

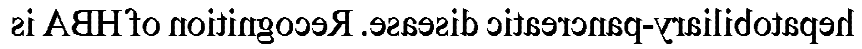
vilqsigonoe эmif-Isэт ło эgsan Ist9dil эnlt ұd bofstiliost

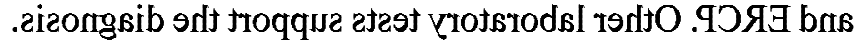

そqojzobriglygoloibsЯ .A

:VֶlqkTgonozstJIU .I

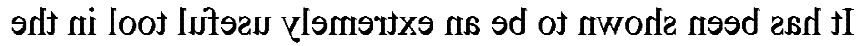

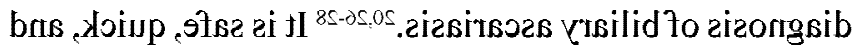

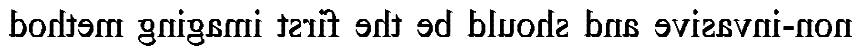
ऐtivitiarrse гirsitsors visilid-ots9tonsq gnivtifnsbi ni tesf aints to

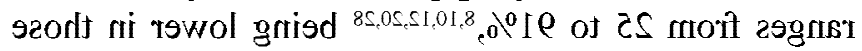

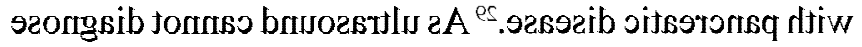

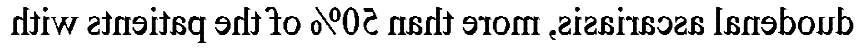


the biliary tree is diagnostic and in those in whom Ascaris cannot be demonstrated, visualization of the worms within the duodenum extends supportive evidence of Ascaris as the possible etiology behind the biliary-pancreatic disease. The sensitivity of ERCP used alone is 53-58\%, while it approaches almost $100 \%$ when used in conjunction with real-time sonography. Cholangiograms reveal various abnormalities like dilatation of the CBD or intrahepatic ducts, motile tubular structures within the biliary tree or irregularity and stricturing of the ductal walls. Cholangiographic features of the worms include long, smooth, linear defects; smooth, parallel filling defects; and curves and loops crossing the hepatic ducts transversely. The worm may be seen lying across the papillary opening or an ulcerated or inflamed papilla may provide a circumstantial evidence of the worm's recent invasion into the biliary tree. ${ }^{10}$ Movement of the ascaride out of the biliary tracts coincides with the resolution of symptoms. ${ }^{9,32}$ Therefore, the highest diagnostic yield is achieved when endoscopy is performed soon after the onset of symptoms.

Earlier studies have recommended early usage of ERCP, since worm extraction through the papillary orifice can also be accomplished in the same setting. ${ }^{10,12,33,34}$ However, the trend of utilizing ERCP as a primary diagnostic tool for biliary ascariasis has evolved whereby it is now utilized mainly for therapeutic purposes. Endoscopic sphincterotomy, balloon extraction of the parasite and bile duct clearance leads to prompt relief of symptoms.

\section{Magnetic resonance cholangio-pancreato-graphy (MRCP):}

It is an alternative diagnostic tool for ascariasis, which has now become the gold standard method for the diagnosis of biliary diseases, replacing ERCP which is reserved for therapeutic modalities. MRCP can be used to provide more details and subtle information of the biliary tree and it is not operator-dependent. Ascaris worms can be seen as hypointense tubular filling defects inside the CBD on MRCP. ${ }^{35,36}$

4. Computed tomographic (CT) scan does not have any proven accuracy in the diagnosis of biliary ascariasis and is discussed only as case reports. At present, its role remains unclear and needs further evaluation.

5. Barium studies, undertaken incidentally, may add corroborative evidence by showing the intestinal worms.

\section{B. LABORATORY TESTS}

Biochemical tests- Variable abnormalities may be seen in liver biochemical tests. Increase in serum alkaline phosphatase is the earliest and most frequent abnormality. ${ }^{8}$ Increase in serum amylase can occur depending on the presence or absence of pancreatitis.

Hematological tests- Abnormalities include modest neutrophilic leukocytosis, eosinophilia and a rise in serum $\operatorname{IgE}$ levels, especially in the migratory phase of Ascaris.

Stool Examination- Detection of fertilized or unfertilized Ascaris eggs (or an adult worm) in the feces is only an indicator of its infestation. However, in the context of a hepatobiliary disease, positive tests help to reinforce the suspicion. The Kato and ocula Miura thick smear is the most effective fecal test, which consists of 30-70 mg of fecal material and has a lot more eggs per female worm than the other smear techniques. ${ }^{37}$

Serological Tests- The use of serological techniques in detection of ascariasis is limited because of extensive cross-reactivity between the antigenic epitopes of different nematodes infective to humans. Ascariasis is associated with elevation of $\mathrm{IgE}$ and $\mathrm{IgG}$ antibodies. These tests provide an indirect indication of Ascaris infection and are not specific for biliary disease. Enzymelinked immunosorbent assay is one of the most sensitive and specific of these tests for detecting specific antibodies. Other tests like radioimmunoassays, agar-gel diffusion and immunoelectrophoretic analysis to detect the presence of IgM antibodies to the Ascaris antigen are also available. Problems with serological tests include difficulty in interpretation due to concomitant infections with Toxocara or the possibility of heterologous reactions with blood group antibodies, and also the complex antigenic structure of Ascaris worm. ${ }^{37}$

Analysis of bile obtained through a nasobiliary or percutaneous transhepatic cholangiographic drain can be used to screen for roundworm ova or fragments but this requires the assistance of interventional radiology or endoscopy. This test has a high diagnostic yield and is particularly helpful in cases where the worm has already moved out of the biliary tree.

\section{MANAGEMENT}

\section{Conservative measures}

Most of the cases of HBA (42-90\%) can be treated with conservative measures and endoscopic worm extraction 
may not be indicated as the Ascaris may move out of the biliary tree spontaneously. ${ }^{8,9,16,38}$ Conservative measures include bowel rest, intravenous fluid therapy, analgesics, antibiotics, and antispasmodics. Conservative treatment is continued usually for 3 days and patient is monitored for improvement in symptoms. During this period migration of the worm should be monitored by serial ultrasonography. Targeted vermifuge against $A$. lumbricoides should be delayed until the worms move out of the biliary tree.

\section{Endoscopic Management}

The use of endoscopic intervention for HBA had brought about a major reduction in the morbidity and mortality of this disease. ${ }^{12,29,34,38-44}$ However, endoscopic intervention /ERCP should be considered only if a patient fails to respond to conservative treatment; or the worm persists (as demonstrated by serial ultrasonography) or has died within the pancreato-biliary tree. ${ }^{45}$ Presence of coexistent strictures or stones within the ducts are also indications for ERCP. Khuroo et al showed that ERCP/endoscopic intervention was only required in $29 \%$ of patients who failed to improve with conservative management. ${ }^{38}$ Indications of early ERCP include patients presenting with pyogenic cholangitis and acute pancreatitis. Maximum utility of endoscopic intervention is derived when the procedure is undertaken in a symptomatic patient. ${ }^{9,29}$ Grasping of the worm by a Dormia basket and extracting it through the papilla leads to a rapid relief of symptoms and a reduction in complication rate. ${ }^{12,24,34,39}$ Sphincterotomy should be avoided if possible and worm extraction attempted by balloon to avoid possible future worm re-invasions. ERCP has a success rate of up to $90 \%$ for worm-extraction. ${ }^{1}$ Infrequent complications of the procedure include fragmentation or incomplete extraction of the worm causing sclerosing strictures of the ducts. In cases where the worm cannot be removed, nasobiliary drainage and supportive treatment with analgesics, antispasmodics and antibiotics can still accomplish biliary decompression.

Location of parasite within the intrahepatic ducts ${ }^{34,38}$ or presence of dead and calcified worms, which get impacted, lead to difficulty in extraction. Worms within the pancreatic duct are also not amenable to easy endoscopic extraction and therefore, these patients carry a poor prognosis. ${ }^{29}$ 'Whirlpool jet technique', which includes injecting a jet of contrast material into the pancreatic duct to flush the roundworm out following which it can be grasped by a basket and then extracted has been described. ${ }^{46}$

\section{Drug therapy}

Drugs effective against $A$. lumbricoides include albendazole, mebendazole and pyrantel pamoate. ${ }^{47}$ Asymptomatic colonization with A. lumbricoides is treated easily with a single 400-mg oral dose of albendazole. Parasite immobilization and death of the helminth are slow and complete clearance of the worm from the gastro-intestinal tract may take up to 3 days. Efficacy of the treatment can be determined by stool examination 1-2 weeks after treatment. However, negative stool samples do not necessarily indicate eradication of the roundworm.

Patients with hepatobiliary ascariasis should be treated with albendazole each day for several days because the worms only become susceptible when they migrate out of the bile duct. ${ }^{48}$ Due to the lack of enterohepatic circulation of albendazole, there is no evident activity of this drug against the worms when they invade the biliary tree. ${ }^{47,48}$ This feature of albendazole is in fact advantageous because if the worms were paralyzed in the biliary tree, they would be unable to pass through the sphincter of Oddi and get trapped in the bile duct.

Direct instillation of the antihelminthic agent into the biliary tree is not recommended. The resultant flaccid paralysis of a worm within the biliary tree eventually leads to its death within the ducts. The macerated worm then elicits a severe inflammatory reaction eventually leading to fibrotic strictures.

Treatment with anti-helminthics has not been shown to be effective in preventing the recurrence of ascariasis, as there is a high rate of re-infection in endemic areas. Even once-monthly courses of anti-helminthics have shown to be ineffective in preventing relapses. ${ }^{8}$ Moreover, long term administration of these drugs may lead to complications.

\section{Surgical therapy}

With the advent of ERCP for management of hepatobiliary diseases, surgery is now rarely required for treatment of HBA. Less than $1 \%$ of HBA cases which are not amenable to endoscopic extraction may need to undergo surgery. ${ }^{10,34,38}$ Other indications include presence of hepatic-ductal or gallbladder ascarides and acute pancreatitis. Some of the surgical methods employed in the management of intractable biliary ascariasis include choledochotomy, choledochoduodenostomy and intraoperative biliary duct syringing to increase the hydrostatic 
pressure and facilitate worm expulsion.

Hepato-jejunostomy may be required for intractable stricturing disease of the biliary ducts, and lobectomy for strictures localized to one lobe of the liver. Flush therapy with normal saline injected through a T-tube has been effectively used to manage post-operative biliary ascariasis. ${ }^{49}$

\section{REFERENCES}

1. Khuroo MS. Ascariasis. Gastroenterol Clin North Am 1996;25(3):553-77.

2. Ochoa B. Surgical complications of ascariasis. World J Surg 1991;15:222-7.

3. Lloyd DA. Massive hepatobiliary ascariasis in childhood. Br J Surg 1981;68:468-73.

4. Gabaldon A, Mofid C, Morishta K, Moskovski S, Sankale M, Standen DD. Control of ascariasis (report of WHO committee). World Health Organ Tech Rep Ser 1967;379:1-39.

5. Schulman A. Biliary ascariasis presenting in the United States. Am J Gastroenterol 1977;68:167-70.

6. Al-Karawi MA, Salam I, Mohammed AE. Endoscopic diagnosis and extraction of biliary ascaris: A case report. Ann Saudi Med 1989;9:80-1.

7. Abu Al-Saud AS. A survey of the pattern of parasitic infestations in Saudi-Arabia. Saudi Med J 1983;4:418-23.

8. Khuroo MS, Zargar SA, Mahajan R. Hepatobiliary and pancreatic ascariasis in India. Lancet 1990;335:1503-6.

9. Khuroo MS, Zargar SA. Biliary ascariasis: A common cause of biliary and pancreatic disease in an endemic area. Gastroenterology 1985;88:418-23.

10. Sandouk F, Haffar S, Zada MM, Graham DY, Anand BS. Pancreatic-biliary ascariasis: Experience of 300 cases. Am J Gastroenterol 1997;92:2264-7.

11. Yang SC, Laube PJ. Biliary ascariasis-report of 19 cases. Ann Surg 1946;123:299-303.

12. Leung JW, Chung SC. Endoscopic management of biliary ascariasis. Gastrointest Endosc 1988;34:318-20.

13. Khuroo MS. Hepatobiliary and pancreatic ascariasis. Indian J Gastroenterol 2001;20(1):C28-32.

14. Mukhopadhyay M. Biliary Ascariasis in the Indian Subcontinent: A Study of 42 Cases. Saudi J Gastroenterol 2009;15(2):121-4.

15. Khuroo MS, Zargar SA, Yattoo GN, Dar MY, Javid G, Khan BA, et al. Sonographic findings in gallbladder ascariasis. J Clin Ultrasound 1992;20:587-91.

16. Gonzalez AH, Regaldo VC, Van den Ende JV. Non-invasive management of Ascaris lumbricoides biliary tract migration: A prospective study in 69 patients from Ecuador. Trop Med Int Health 2001;6:146-50.

17. Gupta R, Agarwal DK, Choudhuri GD, Saraswat VA, Baijal SS. Biliary ascariasis complicating endoscopic sphincterotomy for choledocholithiasis in India. J Gastroenterol Hepatol 1998;13:1072-3.
18. Khuroo MS, Mahajan R, Zargar SA, Pathania AGS, Javid G. Biliary and pancreatic ascariasis: a long term follow-up. Natl Med J India 1989;2:4-7.

19. Langewar DN, Maheshwari MB, Wegholikar UL. Hepatic perforation due to ascariasis. Indian J Pediatr 1993;60:457-9

20. Schulman A. Ultrasound appearances of intra- and extrahepatic biliary ascariasis. Abdom Imaging 1998;23:60-6.

21. Schulman A. Intrahepatic biliary stones: Imaging features and a possible relationship with Ascaris lumbricoides. Clin Radiol 1993;47:325-32.

22. Lim KG, Sellaiah SP. Biliary ascariasis and extrahepatic cholangiocarcinoma: A report of two cases. Singapore Med J 1994;35:400-2.

23. Gupta R, Khanduri A, Agarwal DK, Sawlani V, Baijal S, Choudhuri G. Biliary ascariasis associated with periampullary carcinoma. Indian J Gastroenterol 1995;14:102-3.

24. Javid G, Wani NA, Gulzar GM, Khan BA, Shah AH, Shah OJ, et al. Ascaris-induced liver abscess. World J Surg 1999;23:11914.

25. Paul M. Movements of adult ascaris lumbricoides. Br J Surg 1972;59:437-41.

26. Kamath PS, Joseph DC, Chandran R, Rao SR, Prakash ML, D'Cruz AJ. Biliary ascariasis: Ultrasonography, endoscopic retrograde cholangiopancreatography and biliary drainage. Gastroenterology 1986;91:730-2.

27. Ali M, Khan AN. Sonography of hepatobiliary ascariasis. J Clin Ultrasound 1996;24:235-41.

28. Khuroo MS, Zargar SA, Mahajan R, Bhat RL, Javid G. Sonographic appearances in biliary ascariasis. Gastroenterology 1987;93:267-72.

29. Khuroo MS, Zargar SA, Yattoo GN, Koul B, Khan BA, Dar MY, et al. Ascaris-induced acute pancreatitis. Am J Surg 1992;79:1335-8.

30. Schulman A, Loxton AJ, Hegdenrych JJ, Abdulrahaman KE. Sonographic diagnosis of biliary ascariasis. Am J Roentgenol 1982;139:485-9.

31. Cerri GG, Leite GJ, Simoes JB, Correia Da Rocha DJ, Albuquerque FP, Machado MC, et al. Ultrasonographic evaluation of Ascaris in the biliary tract. Radiology 1983;146:7534.

32. Bhushan B, Watal G, Mahajan R, Khuroo MS. Endoscopic retrograde cholangiopancreatographic features of pancreaticobiliary ascariasis. Gastrointest Radiol 1988;13:32730.

33. Choi TK, Wong J. Severe pancreatitis caused by parasites in the common bile duct. J Trop Med Hyg 1984;87:211-4.

34. Chen YS, Den BX, Huang BI, Xu LZ. Endoscopic diagnosis and management of Ascaris-induced acute pancreatitis. Endoscopy 1986;18:127-8.

35. Adaletli I, Selcuk D, Gulsen M, Savas C, Korman U. MRCP findings of biliary ascariasis before and after medical treatment. Turk J Gastroenterol 2005;16:98-101.

36. Arya PK, Kukreti R, Arya N, Gupta SN. Magnetic resonance of gallbladder ascariasis. Indian J Med Sci 2005;59:208-10. 
37. Pawlowski ZS. Ascariasis. In: Warren KS, Mahmoud AA, editors. Tropical and Geographical Medicine. 2nd ed. USA: McGraw Hill; 1995. p. 369-78.

38. Khuroo MS, Zargar SA, Yattoo GN, Javid G, Dar MY, Boda MI, et al. Worm extraction and biliary drainage in hepatobiliary and pancreatic ascariasis. Gastrointest Endosc 1993;39:680-5.

39. Zargar SA, Khuroo MS. Therapy of biliary ascariasis and its rationale. Gastroenterology 1987;93:668-9.

40. Al-Karawi M, Sanai FM, Yasawy MI, Mohammed AE. Biliary strictures and cholangitis secondary to ascariasis: Endoscopic management. Gastrointest Endosc 1999;50:695-7.

41. El Sheikh Mohamed AR, Al Karawi MA, Yasawy MI. Modern techniques in the diagnosis and treatment of gastrointestinal and biliary tree parasites. Hepatogastroenterology 1991;38:180-8.

42. Chen YS, Den BX, Huang BI, Xu LZ. Endoscopic diagnosis and management of Ascaris induced acute pancreatitis. Endoscopy 1986;181:27-8.

43. Kamiya T, Justiniano M, Duran A, Uechi C. Biliopancreatic ascariasis: Endoscopic approach. J Gastroenterol 2002;37:979.
44. Kamiya T, Morishita T, Reredo R, Marancenbaum C, Montano C. Duodenoscopic management in biliary ascariasis. Dig Endosc 1993;5:179-82.

45. Sanai FM, Al-Karawi MA. Biliary acsariasis: Report of a complicated case and literature review. Saudi J Gastroenterol 2007;13:25-32.

46. Sandouk F, Anand BS, Graham DY. The whirlpool jet technique for removal of pancreatic duct ascaris. Gastrointest Endosc 1997;46:180-2.

47. Smith JW. Anthelmintic drugs. In: Clark WG, Brater DC, Johnson AR, editors. Goth's Medical Pharmacology. 13th ed. St. Louis: Mosby Year Book; 1992. p. 699-703.

48. Elliott DE. Intestinal Infections by Parasitic Worms. In: Feldman M, Friedman LS, Brandt LJ, editors. Sleisenger and Fordtran's Gastrointestinal and Liver Disease. $9^{\text {th }}$ edition. Philadelphia: Elsevier; 2010. p. 1921-40.

49. Wani NA, Shah OJ, Nagash SH. Post-operative biliary ascariasis: Presentation and management - experience. World J Surg 2000;24:1143-5. 


\section{PDF created with pdfFactory Pro trial version www.pdffactory.com}

